\title{
Linewidth tolerance of digital coherent receiver using Viterbi \& Viterbi RF carrier recovery for radio-over-fibre links
}

\author{
Guerrero Gonzalez, Neil; Zibar, Darko; Larsen, Knud J.; Tafur Monroy, Idelfonso
}

Published in:

European Conference on Lasers and Electro-Optics 2009 and the European Quantum Electronics Conference. CLEO Europe - EQEC 2009

Link to article, DOI:

10.1109/CLEOE-EQEC.2009.5191715

Publication date:

2009

Document Version

Publisher's PDF, also known as Version of record

Link back to DTU Orbit

Citation (APA):

Guerrero Gonzalez, N., Zibar, D., Larsen, K. J., \& Tafur Monroy, I. (2009). Linewidth tolerance of digital coherent receiver using Viterbi \& Viterbi RF carrier recovery for radio-over-fibre links. In European Conference on Lasers and Electro-Optics 2009 and the European Quantum Electronics Conference. CLEO Europe - EQEC 2009 IEEE. https://doi.org/10.1109/CLEOE-EQEC.2009.5191715

\section{General rights}

Copyright and moral rights for the publications made accessible in the public portal are retained by the authors and/or other copyright owners and it is a condition of accessing publications that users recognise and abide by the legal requirements associated with these rights.

- Users may download and print one copy of any publication from the public portal for the purpose of private study or research.

- You may not further distribute the material or use it for any profit-making activity or commercial gain

- You may freely distribute the URL identifying the publication in the public portal 


\title{
Linewidth tolerance of digital coherent receiver using Viterbi \& Viterbi RF carrier recovery for radio-over-fibre links
}

\author{
N. Guerrero Gonzalez, D. Zibar, K. J. Larsen, I. Tafur Monroy \\ DTU Fotonik, Department of Photonics Engineering, Technical University of Denmark, DK-2800 Kgs. Lyngby, Denmark
}

Introduction: Transport and distribution of wireless signals over fibre, so called Radio-over-Fibre (RoF), is an important technology in order to realize converged fibre-optic and wireless networks [1]. Recently, we have proposed and experimentally demonstrated a novel DSP based digital coherent receiver for phase-modulated RoF optical links [2]. The RF signal processing in [2] is performed using maximum likelihood RF carrier phase estimation [2]. In this paper, we investigate the performance of the proposed digital coherent receiver in [2] using feedforward Viterbi \& Viterbi RF carrier recovery algorithm in combination with squaring synchronizer. The advantage of the proposed scheme is simplicity since the RF carrier recovery is performed on only one sample per bit due to prior squaring synchronizer which performs timing recovery. We investigate the tolerance of the proposed scheme with respect to laser linewidth using numerical simulations and compare the results to traditional approach using feedforward maximum likelihood RF carrier phase recovery (MLCPE).

Digital coherent receiver and numerical results: The digital coherent receiver is shown in Fig. 1. Once the signal after photodetectors is digitalized, the carrier-recovery digital phase-locked loop removes the difference in frequency and phase between the transmitter and LO lasers from the complex signal. Next, we linearly demodulate the phase encoded RF signal. A quadrature demodulator is used to move the spectrum to baseband and a squaring synchronizer is applied to perform timing recovery. Finally, the Viterbi-Viterbi algorithm is used to estimate RF carrier phase and make subsequent demodulation.

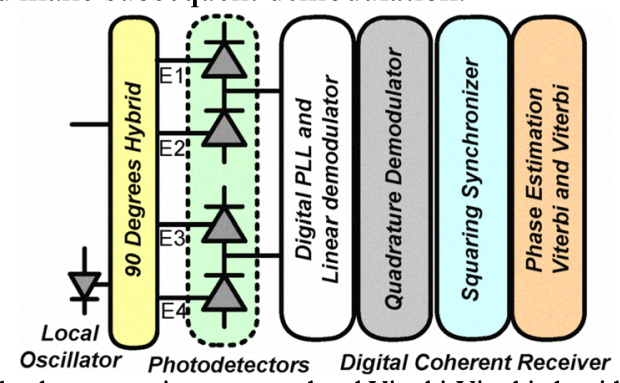

Fig. 1 Digital coherent receiver proposed and Viterbi-Viterbi algorithm for phase recovery

Numerical simulations are performed using VPI software for 1.25 Gbaud QPSK data signal modulating $10 \mathrm{GHz}$ RF carrier. In Fig. 2(a), the BER curves of the demodulated signal are computed as a function of OSNR for laser linewidths increasing from 0 to $10 \mathrm{MHz}$. Figure 2(a) shows that there is only a penalty of app. $2 \mathrm{~dB}$ when increasing the linewidth from 0 to $10 \mathrm{MHz}$ in order to obtain BER at $10^{-4}$, demonstrating the tolerance of our scheme. In Figure 2(b), we compare the proposed RF carrier recovery scheme with the MLCPE in terms of penalty as a function of laser linewidth. It is observed that the proposed scheme in this paper is more tolerant to laser linewidth.
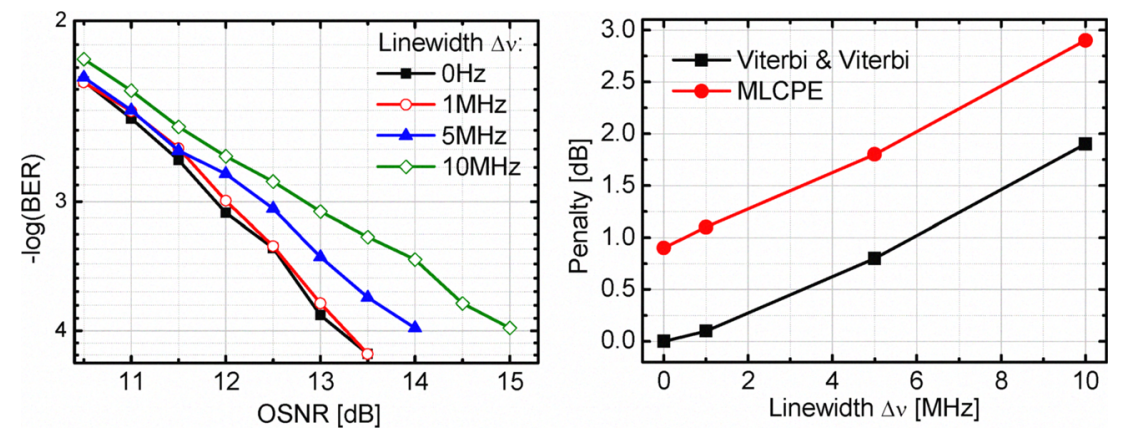

Fig. 2 (a) BER as a function of OSNR for increasing linewidths. (b) Pnealty as a function of linewidth for two different RF carrier recovery schemes

Conclusion: We have shown that the proposed scheme improves the linewitdh tolerance by app. $1 \mathrm{~dB}$ and reduces the number of samples per bit required for the RF carrier recovery to one, compared to the traditional MLCPE.

\section{References}

[1] J. Capmany and D. Novak, "Microwave photonics combines two worlds, " Nature Photonics 1, , pp 319-330, 2007

[2] D. Zibar et al., "Digital coherent receiver for phase-modulated radio-over-fibre optical links," PTL, vol. 21, no. 3, pp. 155-157, 2009 